\title{
Allergenicity Profile of Fifteen Aqueous Allergen Extracts to Selected Allergic Individuals from Pampanga, Philippines
}

\author{
Evelyn V. Totaan, Ph.D.
}

College of Arts and Sciences, Pampanga State Agricultural University, Magalang, Pampanga, Philippines, evtotaan@gmail.com

\section{ABSTRACT}

Allergies are the most common disorders of the immune system, estimated to affect about $20 \%$ of the general population. In the local setting, there is a dearth of information on the sensitization profiles of allergic individuals from Pampanga, Philippines to different allergen sources, thus, evaluation of the total and allergen-specific IgE levels of 100 sera samples from allergic asthma, rhinitis and dermatitis' individuals and 100 sera from non-allergic subjects to fifteen aqueous protein extracts were performed. The aqueous protein extracts prepared from three house dust mite species, three species of cockroaches, two species of fungi, pollens from two species of plants, peanut and four seafoods were quantitated using the BioRad Protein Assay. Sodium Dodecyl Sulfate-Polyacrylamide Gel Electrophoresis (SDS-PAGE) showed multiple bands ranging from 10-250 kDa. Enzyme-linked immunosorbent assay (ELISA) revealed significantly higher mean total serum IgE levels among the allergic groups than non-allergic subjects $(\mathrm{p}<0.0001)$. Unpaired $t$-test results indicated that except for the fungal, tree pollen and crab allergens, there is an extremely significant difference between the mean allergen-specific IgE of allergic subjects compared to the non-allergic subjects for each of the other eleven aqueous allergen extracts, taken separately. Of the allergic subjects, $72.00 \%$ exhibited multiple sensitizations to the fifteen aqueous allergen extracts. This study provides the allergenicity profile of "Kapampangan" allergic individuals which could pave the way for the design of highly specific and accurate diagnostic protocols for allergies among the local patients and may serve as an important basis for immunotherapy.

Key words: Allergenicity, Aqueous allergen extracts, Immunoglobulin E, Sensitization

\section{Corresponding Author: Evelyn V. Totaan}

\section{INTRODUCTION}

Atopic diseases like allergic asthma, allergic rhinitis and atopic dermatitis are the most common disorders of the immune system, estimated to affect about $20 \%$ of the general population. They are the result of complex interactions between largely unknown genetic and environmental mechanisms [1]. Most often, they are caused by immune reactions to common inhaled environmental proteins called allergens. Most common allergen sources include house dust mites, foods, pollens, fungi, animal danders and insect debris [2]. Atopic individuals exposed to allergens from these sources react inappropriately with the production of elevated levels of allergen-specific immunoglobulin-E ( $\operatorname{IgE})$.

The presence of allergen-specific IgEs in the blood serum, is a means to identify the allergens that trigger an allergic response in an individual. For the purpose of allergy diagnosis, allergen avoidance and immunotherapy, the measurement of specific IgEs are widely applied in clinical laboratories. 
Quantitative immunoassays for IgE antibodies may be an adjunct to skin tests and may be used to document allergen sensitization over time and to evaluate the risk of reaction to allergen exposure [3].

At present, there is a dearth of information on the sensitization profiles of allergic individuals from Pampanga, Philippines to different allergen sources. Thus far, no comparative analysis of allergenspecific and total IgE levels among Filipino allergic patients has been reported from this province. Though independent studies have been conducted on the allergenicity of different allergens, no comparative analysis of specific $\mathrm{IgE}$ levels has been performed. It was, therefore, the aim of this study to compare the Ig-E binding activity of the fifteen aqueous protein extracts to selected "Kapampangan" allergic individuals. The result of this study will assist clinicians in establishing the clinical relevance of allergen sensitization. In addition, the result of this study can be used as an important basis for a highly effective and specific diagnostic protocols and immunotherapeutic regiments in the local setting.

\section{MATERIALS AND METHODS}

Study Subjects. Self-structured questionnaires were used to assess symptoms of allergic asthma, allergic rhinitis, and atopic dermatitis. Peripheral blood sera from 100 doctor-diagnosed allergic patients and from 100 controls, aged 0-70 years old, were collected from volunteers living in Pampanga and with parents being pure Filipinos. Patients with history of parasitic infections were not included in the study. Controls included individuals without history of allergy and immediate relatives without allergies. Ten milliliters of peripheral blood was extracted from each patient and were allowed to stand for one hour at room temperature. Serum samples were isolated by centrifugation and transferred into tubes in aliquots and stored at $-20^{\circ} \mathrm{C}$ until use. The study design, conduct of sampling, experimental protocols, questionnaires and associated forms were all approved and authenticated by the Institutional Review Board of the UST Hospital. All the principles of biomedical research involving human subjects, like beneficence, respect for rights and justice, were fully construed before the members of the ethics committee and the participants in the study during the recruitment phase. The mores were also reflected in the explanatory statement and the informed consent form signed by the participants. Likewise, informed consent for the conduct of the study was obtained from all the subjects.

Aqueous Allergen Extracts Preparation. Fifteen aqueous allergen extracts were prepared from three house dust mites (HDM) species (Blomia tropicalis, Bt; Dermatophagoides pteronyssinus, Dp; and Dermatophagoides farina, Df); three species of cockroaches (Periplaneta americana, Pa; Blatella germanica, Bg; and Blatta orientalis, Bo); two species of fungi (Aspergillus fumigatus, Af; and Penicillium chrysogenum, Pc); Saccharum spontaneum, Ss pollen; Leucaena leucocephala, Ll pollen; peanut (Arachis hypogaea, Ah); and seafoods such as shrimp (Penaeus monodon, Pm), crab (Cancer pagurus, $C p$ ), oyster (Ostrea edulis, Oe), and squid (Loglio spp, Ls). Two to ten grams of each of the samples was wrapped in aluminum foil and soaked in liquid nitrogen for 5 minutes. The frozen samples were mechanically ground for at least 5 minutes using a sterile pre-cooled mortar and pestle for 5 minutes. Extraction was performed using $1 \mathrm{X}$ phosphate-buffered saline $(\mathrm{PBS}),(7.4 \mathrm{pH})$ with protease inhibitor cocktail (Sigma-Aldrich, Saint Louis, MO, USA), in a ratio of $1 \mathrm{~mL}: 10 \mu \mathrm{L}$ respectively, added slowly while mechanically grinding the allergen samples. The allergen extract suspension was incubated for 16-20 hours at $4^{\circ} \mathrm{C}$ with constant shaking. Centrifugation at 12,000 rpm for 10 minutes was done using the Sorvall ${ }^{\circledR}$ Super T21 Tabletop Superspeed Centrifuge (Kendro Lab. Products, Newtown, CT, USA). The supernatant (aqueous extract) were transferred in $1 \mathrm{~mL}$ aliquots to pre-labeled microcentrifuge tubes and were stored at $-20^{\circ} \mathrm{C}$ until use.

Protein Quantitation. The aqueous allergen extract preparations were quantitated by BioRad DC Protein Assay (BioRad, Hercules, CA, USA). Ten microliters of each serially diluted Bovine Serum Albumin (BSA) or diluted aqueous extracts thoroughly mixed with $200 \mu \mathrm{L}$ of diluted dye reagent were dispensed in duplicates into a 96-well round bottom assay plate. Incubation at room temperature was 
done for five minutes, followed by optical density reading at $630 \mathrm{~nm}$ using the Bio-Tek ELX800 ELISA reader. A standard curve was prepared by plotting the average (blank-corrected) readings for each BSA standard versus its concentration in $\mu \mathrm{g} / \mathrm{mL}$ and protein concentration of each aqueous allergen extract was then computed.

Sodium Dodecyl Sulfate-Polyacrylamide Gel Electrophoresis. Protein profiles of the prepared aqueous allergen extracts were analyzed by Sodium Dodecyl Sulfate-Polyacrylamide Gel Electrophoresis (SDSPAGE). Separating and stacking gels were prepared following the modified protocols of Laemmli. Protein samples were mixed with 2X SDS-PAGE Sample buffer in a 1:1 ratio and boiled for 10 minutes at $99^{\circ} \mathrm{C}$ (Eppendorf $\circledast$ Thermomixer Compact). Twenty-five microliters of the samples was loaded onto the wells of the stacking gel using a micropipettor. These were separated on a $15 \%$ Tris-Glycine denaturing gel using the Mini PROTEAN electrophoresis system (BioRad, Hercules, CA, USA) run at 110 Volts, $400 \mathrm{~mA}$, for 90 minutes. A Prestained Broad Range Marker (BioRad, Hercules, CA, USA) was used as standard. SDS-PAGE gels were stained with Coomassie brilliant blue R-250, destained using Destaining Solution and laminated. The gels of the samples were compared to the molecular weight markers and molecular sizes were ascertained.

Enzyme-linked Immunosorbent Assay. A Sandwich Enzyme-Linked Immunosorbent Assay (ELISA) was used to screen the total IgE levels of allergic and non-allergic subjects while an Indirect ELISA was used to determine the sensitization profiles of the subjects to each of the fifteen allergen extracts. In Sandwich ELISA, $50 \mu \mathrm{L}(10 \mu \mathrm{g} / \mathrm{mL})$ of unlabeled anti-human IgE (Pharmingen, CA, USA) diluted in coating buffer $\left(0.1 \mathrm{M} \mathrm{NaHCO}_{3}, \mathrm{pH} 8.3\right)$ was coated onto ELISA plates and incubated overnight at $4^{\circ} \mathrm{C}$ in a horizontal shaker (Lab-line Instruments Inc., Melrose Park, III USA). In Indirect ELISA, allergen extracts $(10 \mu \mathrm{g} / \mathrm{mL})$ diluted in coating buffer were dispensed $(50 \mu \mathrm{L} /$ well) to separate into a 96 -well microtiter plates. The plates were incubated at $4^{\circ} \mathrm{C}$ overnight in a horizontal shaker. The plates were washed 3x with Phosphate Buffered Saline - 0.05\% Tween 20 (PBS-T) using the Bio-Tek ELx 50 Auto Strip Washer and were blocked with $1 \%$ BSA (Sigma-Aldrich, Saint Louis, MO USA) diluted in PBS-T for 1 hour at room temperature. ELISA plates were incubated overnight at $4^{\circ} \mathrm{C}$ with human sera diluted $3 \mathrm{x}$ with the blocking buffer followed by $3 \mathrm{x}$ washing and 1 hour incubation at room temperature with biotinylated anti-human IgE (Pharmingen, CA, USA) diluted 1000x in blocking buffer. Plates were then incubated with 2000x dilution of ExtrAvidin-Alkaline Phosphatase conjugate (Sigma-Aldrich, Saint Louis, MO USA) for 1 hour. Finally, colorimetric reaction was performed on washed plates using pnitrophenyl phosphate (Sigma-Aldrich, Saint Louis, MO USA). Absorbance at $405 \mathrm{~nm}$ was determined using a Bio-Tek ELX800 ELISA reader after 60-minute incubation in the dark. Dilutions of purified human IgE (Pharmingen, CA, USA) was used as a standard per plate for the calculation of IgE concentration. Data were analyzed using the GraphPad Prism 5, SPSS version 12, and Microsoft Excel. Total and allergen-specific IgE levels were converted into $\log _{10}$ values to produce normal distribution for statistical analyses (Student's unpaired t-test and one-way Analysis of Variance). Sensitization profile of the 300 allergic individuals to the fifteen aqueous allergen extract preparations was obtained by determining the percentage of positive reactions among the allergic individuals. The mean plus 1 standard deviation of the specific IgE levels of the 100 non-allergic controls was used as cut-off values in determining positive reactions of the allergic individuals against the 15 allergen preparations. Positive reactivity of the 300 allergic patients to any of the 15 allergen sources were then tabulated and compared.

\section{RESULTS AND DISCUSSION}

Aqueous allergen extracts with high protein concentration were prepared from 15 common allergen sources. Total protein concentration detection assay showed that the allergen preparations utilized in this study registered protein contents ranging from $176-695 \mu \mathrm{g} / \mathrm{mL}$ for the HDM extracts, $510-9019$ $\mu \mathrm{g} / \mathrm{mL}$ for the cockroach extracts, 139 and $236 \mu \mathrm{g} / \mathrm{mL}$ for the fungi extracts, 73 and $1051 \mu \mathrm{g} / \mathrm{mL}$ for the 
pollen extracts, $19092 \mu \mathrm{g} / \mathrm{mL}$ for peanut extract and $1524-43294 \mu \mathrm{g} / \mathrm{mL}$ for the seafood extracts. Overall, approximately $400 \mathrm{mg}$ of total protein were isolated for every gram of allergen source (wet weight). Biochemical characterization of most allergens indicate that allergenic molecules are mostly proteins or glycoproteins thus it is necessary that extracts to be used for IgE determination should contain high protein contents [4]. Although allergenic proteins in allergen sources represents less than $1 \%$ of the total protein contents of allergen sources, allergens in minute quantities (femtogram picogram) are enough to sensitize an atopic individual.

SDS-PAGE was used to analyze the protein profile and the quality of the aqueous allergen extract preparations used in the allergen-specific IgE ELISA. Protein bands ranging from 7-250 KDa were detected in the 15 allergen extract preparations (Fig. 1). The presence of intact high molecular weight bands and discrete low molecular weight protein bands indicate a good quality of the allergen extract preparation with minimal degradation. It is important to note that the full-length proteins including the allergen components of the allergen extracts are necessary for the optimum interaction of serum IgEs to their allergen epitopes $[5,6,7,8,9]$.

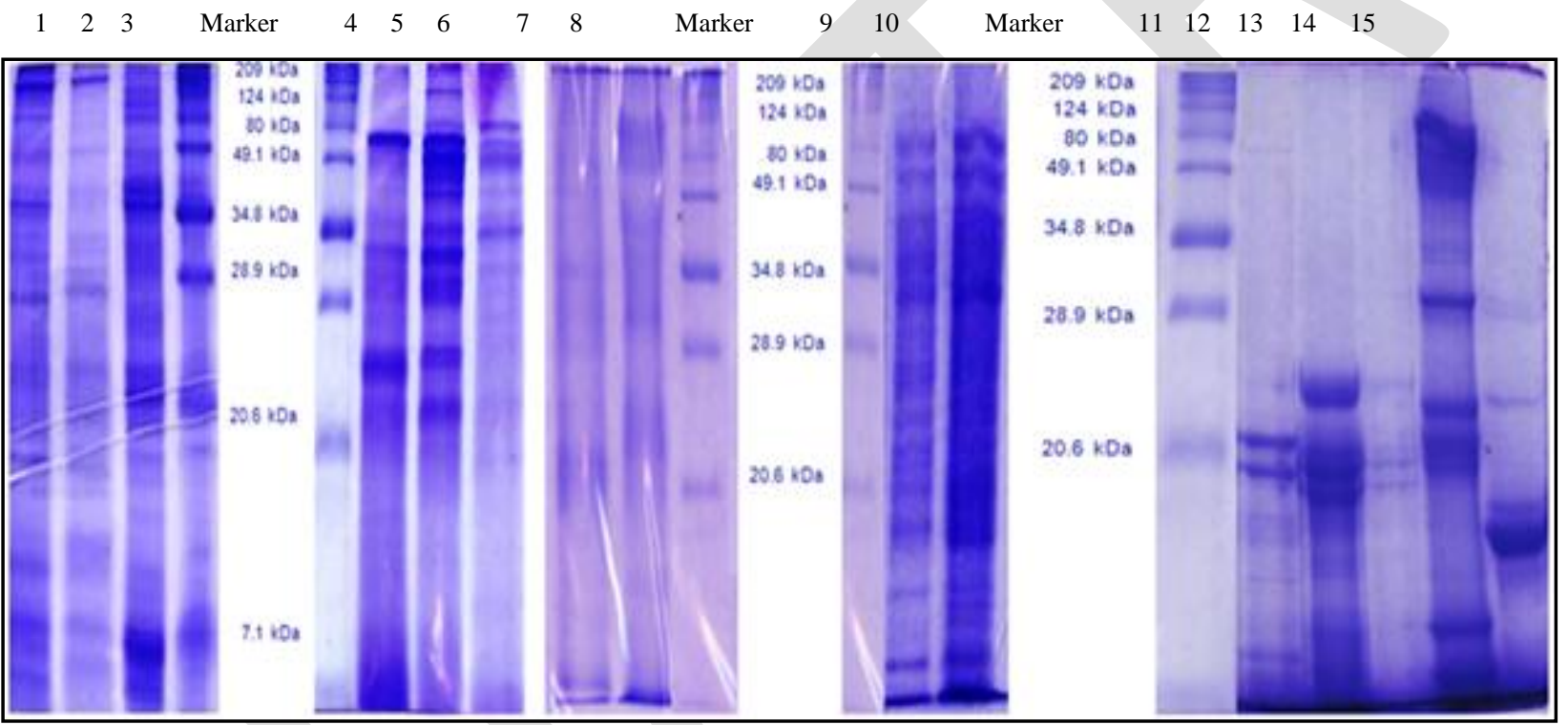

Fig. 1. Sodium Dodecyl Sulfate-Polyacrylamide Gel Electrophoresis profile of the aqueous allergen extracts from Df (1), Dp (2), Bt(3), Pa (4), Bo (5), Bg (6), Ss (7), Ll (8), Af (9), Pc (10), Ah (15), Pm (11), Oe (13), Ls (14), and Cp (12).

Legend:

House dust mites

Df- Dermatophagoides farinae

Dp-Dermatophagoides pteronyssinus

Bt-Blomia tropicalis

Pollens

Ss- Saccharum spontaneum pollen

Ll- Leucaena leucocephala pollen
Cockroaches

$\mathrm{Pa}-$ Periplaneta americana

Bo- Blatta orientalis

Bg-Blatella germanica

Foods

Ah- peanut (Arachis hypogaea)

Pm- shrimp (Peneaus monodon)

Oe- oyster (Ostrea edulis)
Fungi

Af- Aspergillus fumigatus

Pc- Penicillium chrysogenum

Ls- squid (Loglio spp.)

Cp- crab (Cancer pagurus)

Total serum IgE (expressed in IU/mL) was used to assess the allergic conditions of the subjects used in the study. Total IgE level of $\geq 100 \mathrm{IU} / \mathrm{mL}$ of serum among the samples was defined as an atopic state [10]. Unpaired t test showed an extremely significant difference between the mean of the total IgE concentration of allergic and control sera (Fig. 2). The distributions of total IgE levels in normal 
and allergic individuals overlap, but patients who have total IgE less than $10 \mathrm{IU} / \mathrm{mL}$ are very unlikely to exhibit allergic symptoms while those with $200 \mathrm{IU} / \mathrm{mL}$ are very likely to suffer from allergies [11].

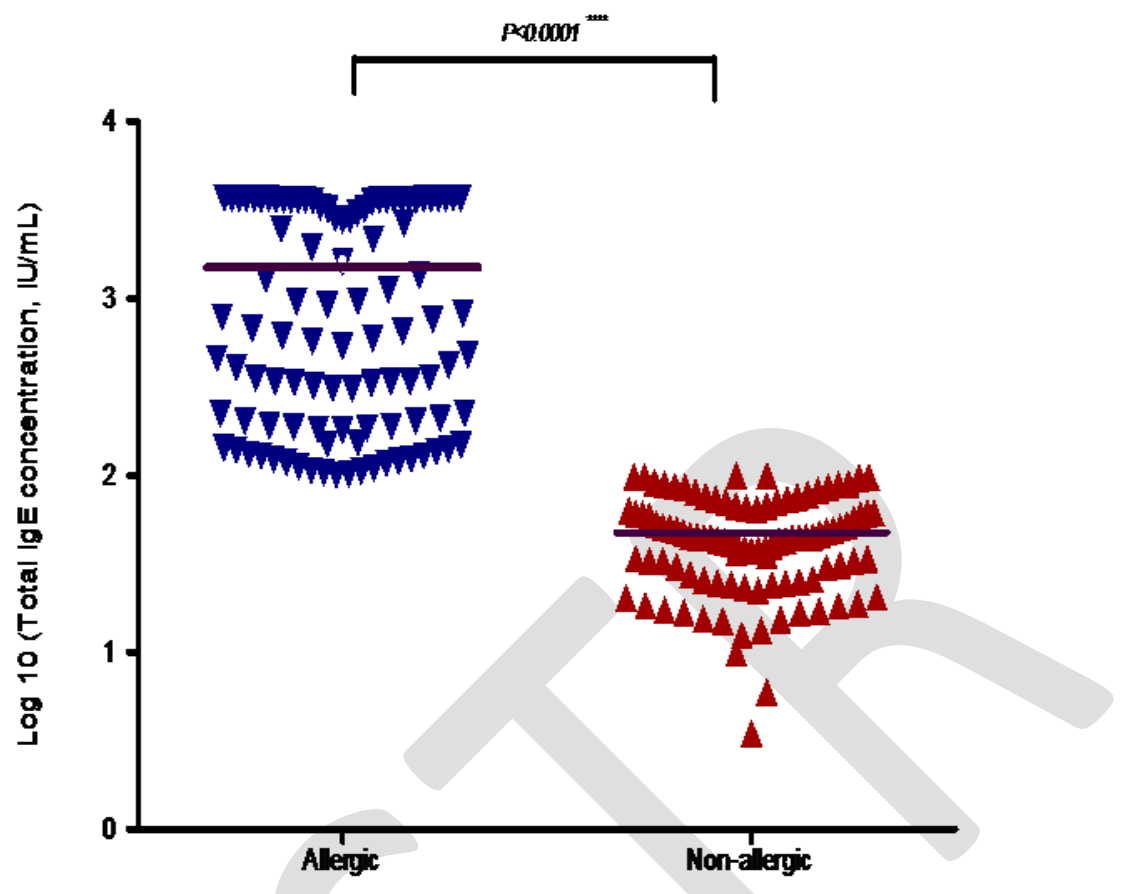

Fig. 2: Dot plot of the log total IgE levels for the 100 qualified allergic and 100 non- allergic subjects as determined by sandwich Enzyme-Linked Immunosorbent Assay. Broken lines indicate the mean IgE concentration of the sera tested.

Allergen-specific IgE levels of the qualified allergic and non-allergic subjects were determined by Enzyme Linked-Immunosorbent Assay. The mean IgE levels of the non-allergic sera +1 standard deviation was used as cut-off values for determining positive reactions. Unpaired t-test results indicate that except for the aqueous fungal, tree pollen and crab allergen extracts, there is an extremely significant difference between the mean allergen-specific IgE of allergic subjects compared to the nonallergic controls for each of the other eleven aqueous allergen extracts, taken separately (Fig.3).
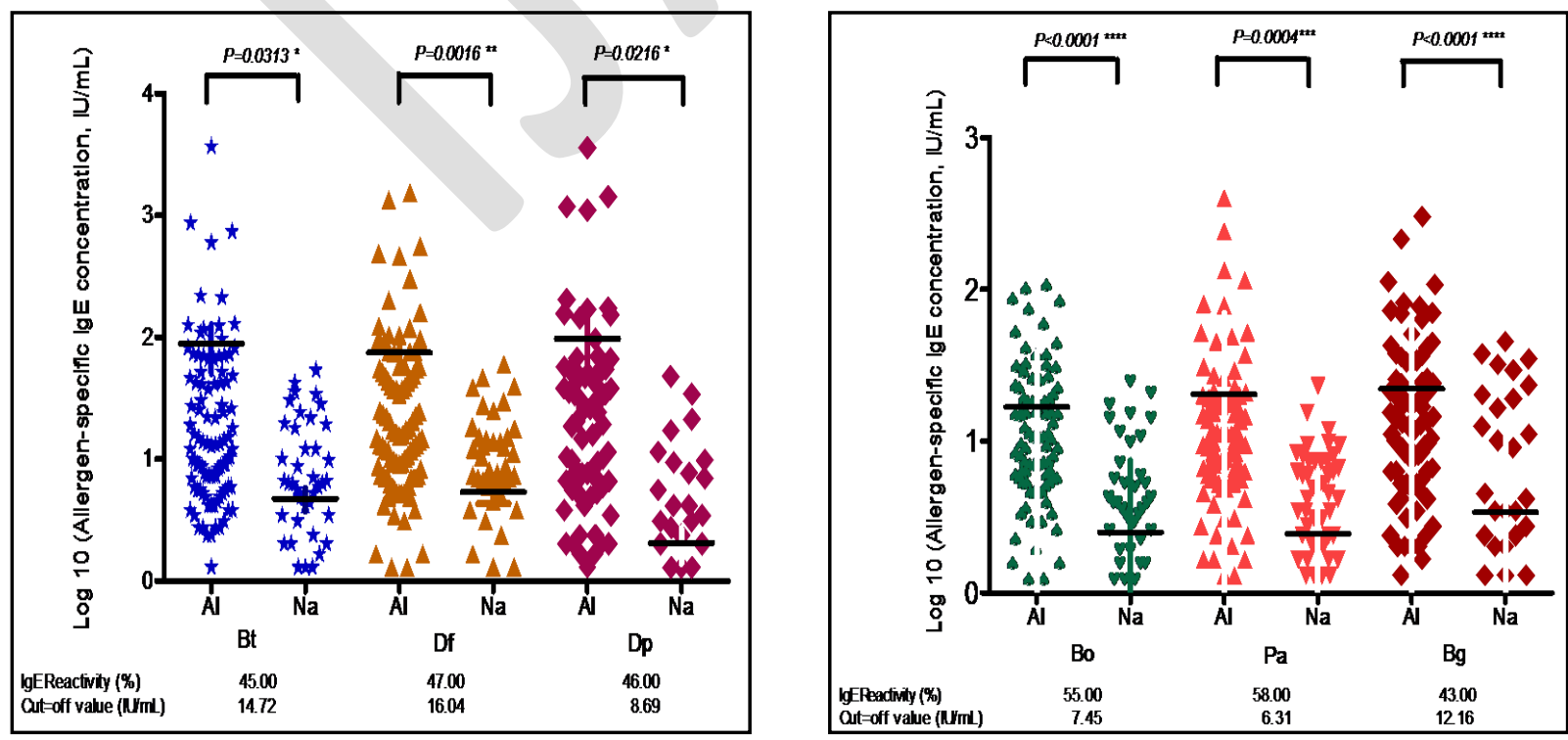



Figure 3: Dot plot of the allergen-specific $\lg E$ levels of the qualified allergic and non-allergic subjects to aqueous house dust mites (A), cockroach (B), fungal and pollen (C) and food (D) allergens. Horizontal lines indicate the mean $\mathrm{lgE}$ concentration of the sera tested.

Of the house dust mite species used, aqueous allergen extracts from Blomia tropicalis and Dermatophagoides farinae exhibit highest IgE reactivity demonstrating the clinical significance of these HDM species as important sources of major allergens that trigger allergic reactions among atopic individuals [12]. With IgE reactivity between 45-47\% (Fig. 3-A), aqueous HDM allergens are indeed major trigger of allergy among the Kapampangans, consistent with previous studies showing that $95 \%$ of the 210 Filipino allergic subjects are sensitized with allergens from any of the three species of HDMs [13]. The high incidence of elevated IgE reactivity greater than $100 \mathrm{ng} / \mathrm{mL}$ or $42 \mathrm{IU} / \mathrm{mL}$ indicates that HDM allergens are clinically potent indices of IgE production that can lead to severe nasal allergic reaction as implicated by earlier studies [14].

Cockroaches are also important sources of allergens that trigger of allergic reactions in Filipinos [15]. In this study, the observed IgE reactivity of cockroach allergen extracts ranged from 43-58\% (Fig. 3B). Aqueous allergen extract from Periplaneta Americana (Pa) exhibited the highest IgE reactivity, followed by Blatta orientalis (Bo) and Blatella germanica (Bg). The high sensitization rate of $\mathrm{Pa}$ and Bo may be attributed to the presence of enormous number of this species in different localities throughout the Philippines, particularly in Pampanga, as a result of favorable reproductive conditions. $\mathrm{Bg}$ can only survive in places with temperature ranging from $21-24^{\circ} \mathrm{C}$ [16]. As with previous studies, the sensitization profiles of Kapampangan allergic individuals to cockroach allergens obtained in this study clearly shows the potential hazards these insects may induce among atopic patients.

Aqueous fungal Penicillium chrysogenum (Pc) and Aspergillus fumigatus (Af) allergen extract preparations registered $12 \%$ and $13 \%$ IgE reactivity (Fig. 3-C), respectively, a manifestation that these fungal species are also important sources of specific allergens that trigger allergic sensitizations among atopic individuals. On the other hand, pollen grains of various grasses and trees are also significant sources of inhalant allergies. Aqueous talahib (Saccharum spontaneum) pollen extract registered 40\% IgE reactivity (Fig. 3-C) which is comparable to that of Blatella germanica. The result is supported by the findings of Bhalla \& Singh (2004) stating that at least $40 \%$ of type 1 allergic 
patients are sensitized against grass pollen allergens thus making grass pollen the most frequent elicitor of allergic symptoms [17]. In contrast, aqueous ipil-ipil (Leucaena leucocephala) pollen extract showed 12\% IgE reactivity (Fig. 3-C). The result further strengthens previous studies revealing that grass pollens still have stronger association to the allergic diseases than tree pollens [18].

Among allergy-causing foods, crustaceans have also been recognized as potent sources of allergens among the Kapampangans (Fig. 3-D). Of these, shrimp with IgE reactivity of 43\%, is indeed the most common causative agent in seafood allergy [19]. Significant differences in the mean allergen-specific IgE levels of the allergic and control subjects were observed. Shrimp allergic patients often have respiratory allergy, allergic rhinitis and atopic dermatitis [20]. In contrast, though crab is a major source of potent allergen (Yunginger et al., 2000), it only registered 10\% IgE reactivity in this study. Peanut is also one of the most common food allergens in both adults and children. With its severity of allergic reaction ( $42 \% \mathrm{IgE}$ reactivity), the persistence of allergic response throughout the lifetime of the individual, and the ubiquitous use of peanut as a protein supplement, peanut allergy is truly a major health concern [21].

Table 1. Summary of the sensitization profiles of the 100 Kapampangan allergic individuals to fifteen aqueous allergen extract preparations. The mean plus 1 standard deviation of the specific IgE levels of the 100 non-allergic controls was used as cut-off values in determining positive reactions of the allergic individuals against the 15 allergen preparations.

\begin{tabular}{|c|c|c|}
\hline & $\begin{array}{c}\text { No. of aqueous } \\
\text { allergen } \\
\text { extracts }\end{array}$ & $\begin{array}{c}\text { Percentage of } \\
\text { positive reaction } \\
(\mathbf{n}=\mathbf{1 0 0})\end{array}$ \\
\hline Single Sensitization & 1 & 11 \\
\hline Dual sensitization & 2 & 7 \\
& 3 & 12 \\
Multiple & 4 & 13 \\
sensitization (three & 5 & 4 \\
or more & 6 & 8 \\
sensitizations) & 7 & 7 \\
& 8 & 9 \\
& 10 & 5 \\
& 11 & 7 \\
& 12 & 2 \\
& 13 & 2 \\
& 14 & 3 \\
\hline
\end{tabular}

The aqueous extracts that showed low IgE reactivity may not contain the allergen components. This could be attributed to the fact that some allergenic proteins may not be soluble in water while others may not be protein/glycoprotein in nature.

Among the allergic subjects, few exhibited multiple sensitizations to the fifteen aqueous allergen extracts (Tables 1 and 2). Of the 100 allergic individuals, $12 \%$ and $13 \%$ positive reactions were 
observed among individuals exposed to 3-4 aqueous allergen extracts. Sensitization to multiple house dust mites' allergens is commonly observed among allergic individuals. This is because different HDM species usually co-inhabit the homes and immediate environment of susceptible individuals, thus causing parallel sensitization. Multiple sensitizations can be a risk factor for the development of allergic diseases and reflects the mean level of that allergen in a particular locality. It heightens immune response and cross-reactivity may occur such that a specific IgE antibody reacts to multiple allergens that belong the same structural family [22].

Table 2. IgE reactivity of the fifteen aqueous allergen extracts to selected Kapampangan allergic individuals

\begin{tabular}{|c|c|}
\hline Aqueous allergen extracts & $\begin{array}{c}\text { Percentage (\%) } \\
\text { IgE Reactivity } \\
(\mathbf{n}=\mathbf{1 0 0})\end{array}$ \\
\hline \multicolumn{2}{|l|}{ House Dust Mites (HDMs) } \\
\hline 1 Blomia tropicalis $(\mathrm{Bt})$ & 45 \\
\hline 2 Dermatophagoides pteronyssinus $(\mathrm{Dp})$ & 46 \\
\hline 3 Dermatophagoides farinae (Df) & 47 \\
\hline \multicolumn{2}{|l|}{ Cockroaches } \\
\hline 4 Periplaneta americana $(\mathrm{Pa})$ & 58 \\
\hline 5 Blatta orientalis $(\mathrm{Bo})$ & 56 \\
\hline 6 Blatella germanica $(\mathrm{Bg})$ & 43 \\
\hline \multicolumn{2}{|l|}{ Fungi } \\
\hline 7 Aspergillus fumigatus (Af) & 12 \\
\hline 8 Penicillium chrysogenum $(\mathrm{Pc})$ & 13 \\
\hline \multicolumn{2}{|l|}{ Pollens } \\
\hline 9 Saccharum spontaneum) (Ss) & 40 \\
\hline 10 Leucaena leucocephala) (Ll) & 12 \\
\hline \multicolumn{2}{|l|}{ Foods } \\
\hline 11 Peanut ( Arachis hypogaea) (Ah) & 42 \\
\hline 12 Shrimp (Penaeus monodon) (Pm) & 43 \\
\hline 13 Oyster (Ostrea edulis) (Oe & 13 \\
\hline 14 Squid (Loglio spp.) (Ls) & 13 \\
\hline 15 Crab (Cancer pagurus) (Cp) & 10 \\
\hline
\end{tabular}

\section{CONCLUSION}

The clinical importance of allergens from the fifteen aqueous allergen extracts as triggers of allergic sensitization among selected Filipino allergic patients had been shown in this study. The results obtained in this study clearly illustrates that among the Filipino allergic patients, multiple sensitizations occur. Despite the presence of multiple sensitizing agents, however, HDM allergens are still the most clinically important sources of allergens in the local setting.

The study could pave the way for the design of highly specific and accurate diagnostic protocols for allergies among the local patients and may serve as an important basis for vaccine preparation. 


\section{REFERENCES}

[1] T. F. Chan, K.M. Ji, A. K. Y Yim, X.Y. Liu, J.W. Zhou, et al., The draft genome, transcriptome, and microbiome of Dermatophagoides farinae reveal a broad spectrum of dust mite allergens, J Allergy Clin Immunol, Vol 135, p. 539-548, 2015.

[2] N. Abbas, A. Raheem and F. Ghani. Environmental and food allergens reactivity and its association with total IgE, age and gender in Karachi, Pakistan. J. Allergy Ther, Vol. 6 (15), p. $1-6,2015$.

[3] J.W. Yunginger, S. Ahlstedt, P.A. Eggleston, H.A. Homburger, H.S. Nelson, D.R. Ownby, T.A.E. Platts-Mills, H.A. Sampson, S.H; Sicherer, , A.M. Weistein, P. B. Williams, R.A. Wood and R.S. Zeige, Quantitative IgE antibody assays in allergic diseases, J. Allergy Clin Immunol. Vol. 105, p. 1077-1083, 2000.

[4] J.D.A. Ramos, N. Cheong, A.S.M. Teo, I.C. Kuo, B.W. Lee, and J.Y. Chua, Production of monoclonal antibodies for immunoaffinity purification and quantitation of Blot $t 1$ allergen in mite and dust extracts, Clin Exp Allergy. Vol. 34, p. 604-610. 2004.

[5] W.R.W. Smith, B.J. Hales, K.L. Mills, and R.M. O’Brien, Characterization and immunobiology of house dust mite allergens, Int Arch Allergy Immunol. Vol. 129, p. 1-18. 2002.

[6] E. Fernandez-Caldaz and V.I. Calvo, Mite Allergens. Curr. Allergy and Asthma Reports. Vo. 5, p. 402-410, 2005.

[7] L.G. Arlian, Arthropod Allergens and Human Health. Annu. Rev. Entomol., Vol 7, p. 395-433, 2002.

[8] P.N. Diraphat, W. Sookrung, P., Chaicumpa, P., Pumhirun,, Vichyanond, and P. Tapchaisri. Recombinant American cockroach component, Per a 1, reactive to IgE of allergic Thai patients. Journal of Allergy, Asthma \& Immunology, 21, p. 11-20, 2003.

[9] R. Valenta, The future of antigen-specific immunotherapy of allergy. Opinion. Perspectives, Vol. 2, p. 445-452, 2002.

[10] W. Uter, C. Stock, A. Pfalberg, F. Guillen-Grima, I. Aguinaga-Ontoso, C. Brun-Sandiumenge, and A. Kramer. Association between infections and signs and symptoms of 'atopic' hypersensitivityresults of a cross-sectional survey among first-year university students in Germany and Spain. Allergy. Vol. 58(7), p. 580-584. 2003.

[11] H.S. Nelson, J. Areson, and R. Riesman. A prospective assessment of the remote practice of allergy: comparison of the diagnosis of allergic disease and the recommendations for allergen immunotherapy by board-certified allergists and a laboratory performing in vitro assay. J Allergy Clin Immuno. Vol. 92(3), p. 380, 1993.

[12] I. L. Siman, L. M. de Aquino, L.H. Ynoue, J.S. Miranda, A.C.A.M. Pajuaba, J.P. Cunha-Junior, D.A.O.Silva, and E.A. Taketomi, Allergen-specific IgG Antibodies purified from mite-allergic patients sera block the IgE recognition of Dermatophagoides pteronyssinus antigens: an invitro study, Clinical and Developmental Immunology, Vol 2013, p. 1-11, 2013. 
[13] J.D. Ramos, M.S. Castillo, M. del Rosario, M.Gapay, T. Go, and E. Kamantigue. Allergenicity and cross-reactivity of 3 house dust mite species among allergic Filipino allergic patients. Philippine Journal of Science, Vol. 136(2), p. 139-146, 2007.

[14] W.R. Thomas. House dust allergy and immunotherapy. Human Vaccines and Immunotherapeutics, Vol. 8(10), p. 1469-1478, 2012.

[15] J.W. Yunginger, S.Ahlstedt, P.A. Eggleston, H.A. Homburger, H.S. Nelson, D.R. Ownby, T.A.E. Platts-Mills, H.A. Sampson, S.H. Sicherer, A.M. Weistein, P. B. Williams, R.A. Wood, and R.S. Zeiger. Quantitative IgE antibody assays in allergic diseases. J. Allergy Clin Immuno, Vol. 105, p. 1077-1083, 2000.

[16] J.D. Ramos, M. Arias, A. Hocson, J. Noguera, and K. Ojeda. Sensitization profiles of selected atopic Filipino patients to cockroach allergens. The Philippine BIOTA, Vol. 40(1), p. 14-23, 2007.

[17] P.L. Bhalla, and M.B. Singh. Engineered allergens for immunotherapy. Curr Opin Allergy Clin Immunol, Vol. 5: 569-573, 2004.

[18] S.H. Arshad, S.M. Tariq, S. Matthews, and \& E. Hakim. Sensitization to common allergens and its association with allergic disorders at age 4 years: a whole population birth cohort study. Pediatrics, Vol. 108(2), p. E33, 2001.

[19] J.B. Abramovich, S, Kamath, N. Varese, C. Zubrinich, A.L. Lopata, et.al. IgE reactivity of blue swimmer carb tropomyosin, Pro p 1, and other allergens; cross-reactivity with black tiger prawn and effects of heating. PLOS ONE, Vol. 8(6), p. e67487, 2013.

[20] C.B. Daul, J.E Morgan, and S.B. Lehrer.). Hypersensitivity reactions to crustacean and mollusks. Clin. Review Allergy, Vol. 11(2), p. 201-222, 1993.

[21] G. du Tolt, P.H. Sayre, G. Roberts, K. Lawson, M.L. Sever, et al. The allergen-specificity of early consumption and the impact on the development of allergic disease in the LEAP study cohort. J. Allergy Clin Immunol, doi: 10.1016/j.jaci.2017.09.034. 2017.

[22] J.A. Jenkins, S. Griffiths-Jones, P.R. Shewry, H. Breiteneder, and E.N. Mills. Structural relatedness of plant food allergens with specific reference to cross-reactive allergens: an in silico analysis. J. Allergy Clin Immunol. Vol. 115, p. 163-170, 2005. 